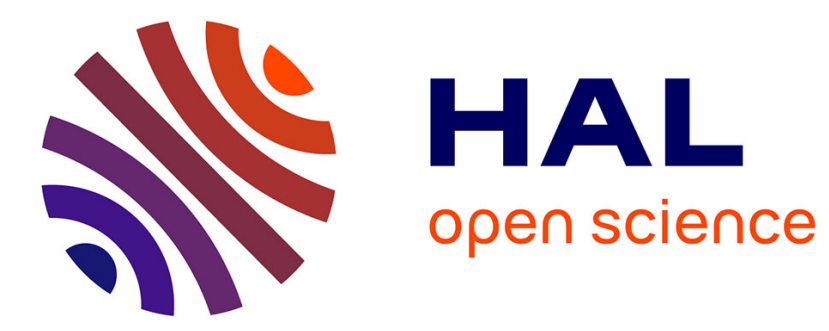

\title{
Objectives and status of EUROfusion DEMO blanket studies
}

\author{
L.-V. Boccaccini, G. Aiello, J. Aubert, C. Bachmann, T. Barrett, A. del Nevo, \\ D. Demange, L. Forest, F. Hernandez, P. Norajitra, et al.
}

\section{- To cite this version:}

L.-V. Boccaccini, G. Aiello, J. Aubert, C. Bachmann, T. Barrett, et al.. Objectives and status of EUROfusion DEMO blanket studies. ISFNT 12 - International Symposium on Fusion Nuclear Technology, Sep 2015, Jeju, South Korea. cea-02509666

\section{HAL Id: cea-02509666 https://hal-cea.archives-ouvertes.fr/cea-02509666}

Submitted on 17 Mar 2020

HAL is a multi-disciplinary open access archive for the deposit and dissemination of scientific research documents, whether they are published or not. The documents may come from teaching and research institutions in France or abroad, or from public or private research centers.
L'archive ouverte pluridisciplinaire HAL, est destinée au dépôt et à la diffusion de documents scientifiques de niveau recherche, publiés ou non, émanant des établissements d'enseignement et de recherche français ou étrangers, des laboratoires publics ou privés. 


\title{
Objectives and status of EUROfusion DEMO blanket studies
}

\author{
L.V. Boccaccini ${ }^{\mathrm{a}}$, G. Aiello ${ }^{\mathrm{b}}$, J. Aubert ${ }^{\mathrm{b}}$, C. Bachmann ${ }^{\mathrm{c}}$, T. Barrett ${ }^{\mathrm{d}}$, A. Del Nevo $^{\mathrm{e}}$, D. Demange ${ }^{\mathrm{a}}, \mathrm{L}$. \\ Forest $^{\mathrm{b}}$, F. Hernandez ${ }^{\mathrm{a}}$, P. Norajitra ${ }^{\mathrm{a}}$, G. Porempovic ${ }^{\mathrm{f}}$, D. Rapisarda ${ }^{\mathrm{g}}$, P. Sardain ${ }^{\mathrm{h}}$, M. Utili ${ }^{\mathrm{e}}$, L.Vala $^{\mathrm{i}}$
}

\author{
${ }^{a}$ Karlsruhe Institute of Technology (KIT), Germany \\ ${ }^{b}$ CEA-Saclay, DEN, DM2S, SEMT, F-91191 Gif-sur-Yvette, France \\ 'EUROfusion, PPPT, Garching, Germany \\ ${ }^{d}$ CCFE, Abingdon OX14 3DB, UK \\ ${ }^{e}$ ENEA CR Brasimone, 40032 Camugnano, (BO), Italy \\ ${ }^{f}$ Fuziotech Engineering Ltd, Hungary. \\ ${ }^{g}$ CIEMAT, Avda. Complutense 40, 28040 Madrid, Spain \\ ${ }^{h}$ CEA/IRFM, 13115 Saint-Paul-lès-Durance, France \\ ${ }^{i}$ Centrum výzkumu Řež, 25068 Husinec- ̌̌ež, Czech Republic
}

\begin{abstract}
The design of a DEMO reactor requires the design of a blanket system suitable of reliable T production and heat extraction for electricity production. In the frame of the EUROfusion Consortium activities, the Breeding Blanket Project has been constituted in 2014 with the goal to develop concepts of Breeding Blankets for the EU PPPT DEMO; this includes an integrated design and R\&D program with the goal to select after 2020 concepts on fusion plants for the engineering phase. The design activities are presently focalized around a pool of solid and liquid breeder blanket with helium, water and PbLi cooling. Development of tritium extraction and control technology, as well manufacturing and development of solid and PbLi breeders are part of the Programme.
\end{abstract}

Keywords: breeding blanket, DEMO, tokamak, in-vessel components, PbLi loops, tritium extraction

\section{Introduction}

The EU fusion roadmap Horizon 2020 [1] foresees a Demonstration Fusion Power Reactor (DEMO) to follow ITER as the remaining crucial step towards the commercial exploitation of fusion power. Rationale of the plant configurations used in the European Power Plant Physics and Technology (PPPT) programme and the strategical development plant adopted in these studies can be found in [2].

Major requirements of the PPPT-DEMO plant are the production of the tritium necessary to sustain the thermonuclear reaction and the delivery of several hundreds of MW of electrical power in net around 2050. For these tasks the breeding blanket (BB) is the key components using the neutron of the fusion reaction to produce tritium (reaction with $\mathrm{Li}$ ) and converting the energy of neutron, particles and photons coming out from the burning plasma in thermal energy suitable for power generation systems. To achieve these goals, the blanket system shall occupy more than $85 \%$ of the invessel surface/volume surrounding the plasma, collecting a similar percentage of the total fusion energy (around $2.0 \mathrm{GW}$ in the present plant lay-out) in its heat removal systems. The Breeding blanket requires large external auxiliary systems to perform its functions, namely the Primary Heat Transfer System (PHTS), the power generation system (PGS), the tritium extraction system (TES). For these reasons the selection of the type of blanket is a strategical choice that constraints strongly the whole DEMO plant design, its safety features and economic viability.
Also if the present PPPT DEMO configuration is setting specific requirements to the blanket design, (requiring a dedicated work of adaptation and integration), the breeding blanket development can refers to a very long tradition of studies. In EU, Japan, USA and Russia Federation, large blankets studies has been conducted since the 80-teens years in international and national programmes; more recently other countries (China, Korea and India) have joined the fusion community participating to ITER construction and to the development of own Roadmaps for the DEMO and commercial power plant. Furthermore, all these countries are participating to the Test Blanket Programme, where six blanket prototypes (the so called Test Blanket Modules, TBM) will be tested in 3 Equatorial Ports of ITER; the programme aims to gain operational information on the behavior of blanket mock-ups, materials, processes and technologies in the integrated fusion environment offered by ITER [3].

\section{The BB Project in EUROfusion}

The Breeding Blanket Project (labelled also WPBB) was constituted in April 2014 inside the Consortium EUROfusion. It is included in the PPPT Project together with other Projects dedicated to the different systems constituting a fusion power reactor (e.g. Heat and Current Drive, Magnet, Divertor, Balance of Plant) and to general topics like Safety, Remote Maintenance and Materials. The different Projects are coordinated through a reactor integration Project at level of PMU Garching. 
The major goal of the WPBB (in the Horizon 2020 framework) is to complete the design at conceptual level of the breeder blanket systems (including TES) compatible with the PPPT DEMO requirements and interfaces. It is currently assumed that after 2020 one or two plant concepts will be selected for starting an engineering phase that should lead to a constructive design of a fusion power plant in the time foreseen by the Roadmap. The WPBB programme in 2014-2020 has as milestones: end 2015 the first release of requirements and interfaces relatives to the blanket systems, end 2017 a consolidated design of the candidate blankets and end 2019 a final conceptual design of these systems. The design work is supported by a relatively large $R \& D$ programme to consolidate the knowledge of the proposed technologies, to assess feasibility, maturity and costs.

Following the recommendations of the Roadmap, investigations on 4 blanket concepts have been included in the WPBB programme. They are the two blanket concepts selected to be tested in the TBM Programme in ITER [4], namely the Helium Cooled Pebble Bed (HCPB) and the Helium Cooled Lithium Lead (HCLL) concepts. In addition, to extend the selection basis according to a strategy of risk minimization, a watercooled concept, i.e. the Water Cooled Lithium Lead (WCLL) and a more advanced concept, i.e. the Dual Coolant Lithium Lead (DCLL) have been included in the study. All these concepts have been extensively investigated in the EU BB programme, in particular during the DEMONET studies (1992-1995) and the PPCS (1999-2004) [5]. An introduction to the characteristic of these blankets concepts can be found in [6].

The WPBB is organized in 9 Work Areas (WA); the first 4 areas are related to the work of design teams dedicated to the development of one of the considered blanket design, the other 4 WAs are cross technologies used by several blanket concepts (like PbLi systems, tritium extraction and control, blanket manufacturing and FW design and performances). The $9^{\text {th }}$ area refers to the group in KIT supporting the Project Leader in Technical Coordination, Project Management, System Engineering and Configuration (see Table I). Seven Research Units (RU) are involved in the WPBB activities, namely KIT (that has the coordination role), ENEA, CVR (IPP.CR), CIEMAT, CEA, CCFE, Wigner RCP (HAS); order according to the ppy involvement in 2014-2018.

Table I: Work Packages in the BB Project (underlined the RU with coordination role in the WP)

\begin{tabular}{lll} 
ID & WA Description & RUs involved \\
\hline WP1 & $\begin{array}{l}\text { HCPB Blanket Design } \\
\text { and ceramic breeder } \\
\text { development }\end{array}$ & KIT, CIEMAT, HAS \\
WP2 & HCLL Blanket Design & $\underline{\text { CEA, IPP.CR, HAS }}$ \\
WP3 & $\begin{array}{l}\text { WCLL Blanket Design } \\
\text { and water cooling } \\
\text { technology }\end{array}$ & \\
&
\end{tabular}

\section{development}

WP4

DCLL Blanket Design CIEMAT, IPP.CR, KIT
and Flow Channel Insert development

WP5 PbLi Technology ENEA, KIT, CIEMAT, development $\quad$ IPP.CR

WP6 Tritium Technology KIT, ENEA, CIEMAT, development $\quad$ CCFE

WP7 Blanket manufacturing CEA, KIT, IPP.CR

WP8 FW/Limiter design $\quad \underline{\text { CCFE, KIT, IPP.CR }}$

WP9 Supporting Group $\quad \underline{\text { CEA }}$, KIT

\section{Design approach}

Requirements and rationale deriving from integration of the blanket design in the reactor plant are described in detail in another paper [7]. Here it is recalled that the blanket system has to be designed for a lifetime corresponding to neutron damages of 20 dpa (a second set for $50 \mathrm{dpa}$ ); this means that one scheduled replacement of the whole blanket system is necessary in the life of the reactor (about $70 \mathrm{dpa}$ ). The blankets shall be adapted to a reactor maintenance system based on a remote handled vertical replacement through large vertical ports [8]. According to this concept (see Figure 1) each blanket sector (toroidal portion between two TFcoils) is vertically divided into 3 outboard (OB) and 2 inboard (IB) segments; for an 18-TF-coils-reactor this means 90 individual segments. At the present stage of design the architecture of each segment follows the principle of the Multi-Module-Segment (MMS) concept; a blanket segment is formed by a robust Back Supporting Structure (BSS) that support modules (boxes) that contain the breeder zone (BZ) and the First Wall (FW). The BSS includes also the main manifold system that feeds the modules and connects the PHTS outside the vacuum vessel.

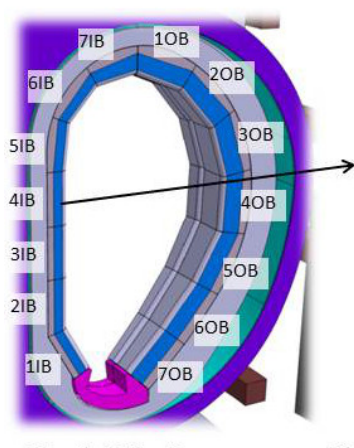

Blanket Sector

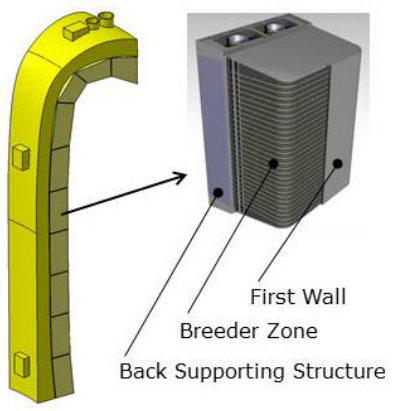

Blanket Segment

Blanket Module
Fig. 1: Typical blanket segmentation for a vertical maintenance system and MMS architecture.

The complete set of requirements on which the blanket system should be designed is still under completion and evolves in parallel with the design; a first version of the BB System Requirement Document (SRD) has been already produced in 2014 and a more complete version will be issued at the end of 2015. Even 
if incomplete the SRD contains already a set of main requirements that are followed by each design team; this includes nuclear, thermo-hydraulics and structuralmechanical requirements,

\subsection{Nuclear requirements}

A main requirement for the DEMO reactor is to produce all the $\mathrm{T}$ necessary for the thermonuclear reaction, not relying to any external sources (apart from several kilograms of T necessary to start the reactor operations).

As blankets are supposed to be the only components to breed $\mathrm{T}$, the $\mathrm{T}$ self-sufficiency can be achieved only with an accurate nuclear design of this system. In particular breeder and neutron multiplier materials shall be located in proximity of the plasma flux and neutron absorption materials shall be minimized in the breeding zone; e.g. manifolds have to be located in the rear part of the blanket box. In particular the amount of steel that is used as structural material has to be reduced; amount of steel larger than $12-15 \%$ can degrade the tritium breeding ratio (TBR) to unacceptable levels. The paper [9] shows the challenges related to achieve the $\mathrm{T}$ self- sufficiency in the four PPPT concepts, comparing the blanket design versions produced in 2014. Many of the recommendations of this paper have been already implemented in the 2015 design showing that all the concepts have the potentiality to fulfil the TBR requirements. Even if in the current PPPT DEMO plant design the $\mathrm{VV}$ takes almost all the task of shielding for the magnets, blankets have still to protect the VV against damages (dpa < 2.75), excessive heating and, depending on the materials, to reduce the activation of the $\mathrm{VV}$ structures [7]. In addition they will be required to shield effectively in correspondence of the weak points of the $\mathrm{VV}$, like in correspondence of the several ports.

\subsection{Thermo-hydraulic requirements}

The design of the blanket has to ensure an effective cooling of all the parts under surface and neutron volumetric heat to cope with temperature limits of the materials. EUROFER steel shall be kept under $\sim 550^{\circ} \mathrm{C}$, solid breeders under $920^{\circ} \mathrm{C}$, beryllium under $650^{\circ} \mathrm{C}$ and $\mathrm{PbLi}$ under $\sim 550^{\circ} \mathrm{C}$ (at least at the interface with steel) in order to reduce the corrosion issues.

The cooling scheme elaborated for all the blankets is able to perform well in the breeding zone allowing a fully integration in the PHTS. On the contrary the power handling requirements of the first-wall are still subject to large uncertainties, complicating the thermo-hydraulic integration. Work is under way to develop a DEMO wall load specifications which will provide poloidally resolved estimates of a wide range of static and transient loads (see section5.4). For the FW design, three architecture options have been proposed, ranging from i) a fully thermo-hydraulically and mechanically integrated option (current reference design), through ii) a thermohydraulically decoupled one, to iii) a fully (also mechanically) decoupled option (see Figure 2). The adoption of these different configurations will depend on the local loads acting on the blanket surface. For relatively low surface loads (under 0.5-1.0 $\mathrm{MW} / \mathrm{m}^{2}$, depending on the used coolant) and uncertainties in the range of $\pm 15 \%$ the solution i) seems possible while for higher uncertainties the solution ii) should be preferred. Solution iii) could be adopted to reduce thermal and EM loads or if the lifetime of the FW components falls below the limits prescribed for the remaining blanket (e.g for the use of other structural materials than EUROFER) requiring a local replacement.


Fig. 2: Possible design options for the blanket FW: i) integrated design, ii) hydraulic decoupled, ii) fully decoupled.

\subsection{Structural-mechanical requirements}

The structures forming the blanket have to withstand the mechanic loads coming mainly from the coolant pressure, thermal stresses and electromagnetics loads. Characteristic of all these blanket designs is the presence of high pressure coolants (8 MPa for helium and 15.5 MPa for water) in small channels imbedded in plates or in independent pipes. The structural assessment is performed following mainly RCC-MRx rules, in particular according to [10] should be assessed following: immediate plastic collapse and plastic instability, immediate plastic flow localization, thermal creep, ratcheting and fatigue.

Critical for the mechanical design is the assessment of the box under in-box LOCA. During operation the box contains the breeder materials at low pressure $(<0.2 \mathrm{MPa}$ for helium purge in HCPB, $1 \mathrm{MPa}$ of hydrostatic load for $\mathrm{PbLi}$ ) being fully separated from the high pressure cooling system. In case of a rupture of a separating wall the box can pressurize at the coolant pressure. Design requirements are still in discussion, but a design according to Level C or D of the design rules is envisaged. The reinforcements necessary to ensure the box stability are to be designed accurately to avoid increasing of the amount of steel in the BZ with consequences for the TBR.

EM forces constitute another typical load challenge for the tokamak reactor; they are caused by electrical currents induced by magnetic transients interacting with magnetic fields (Lorentz forces) or simply by the stationary interaction of magnetic fields with magnetic materials (Maxwell forces). In particular transients related to the disruption of the 10-MA-plasma currents, can produce large eddy current in the surrounding blanket structures, with resultant torques of tens of $\mathrm{MNm}$ on the major components [11]. These forces are in particular a challenge for the attachment system of the blankets to the VV. Large internal force components can also affect the box integrity; a study is ongoing to assess the performance of the MMS design (e.g. the BSS).

\section{Status of the BB concepts}


The four blanket concepts described in Section 2 are currently designed for adaptation to the PPPT-DEMO. Since end 2014 a Design Description Document for each concept and related CAD drawings is available. Performance analyses on neutronics, thermo-hydraulics and structural mechanics are performed to validate the design.

\subsection{The HCPB concept}

It is a solid breeder concept that uses a ternary Liceramics as breeder and beryllium as neutron multiplier material; it was already present and deeply investigated in the DEMONET Studies [12] and in PPCS [13].

The adaptation of the design to the PPPT-DEMO, started in 2012 with a first version based on the robust "beer-box" architecture used also for the TBM and with a segmentation in 10 boxes per segment. The results, however, were poor in term of TBR [14]. As the HCPB concept is characterised by a relatively moderated spectrum (due to the presence of large amount of beryllium), it is very sensitive to steel content. The adaptation of the design to the PPPT-DEMO plant required a completely new architecture of the breeder zone. By eliminating the vertical stiffening grid system and the breeder units of the "beer box" concept, it is possible to feed the FW directly from the back supporting structure manifold, reducing the intermediate level of box manifold. This new architecture has resulted in a steel amount reduction of about $11 \%$, in the BZ.

In addition this results in an increase of the radial thickness of the BZ of about 55\% at the OB modules and $79 \%$ at the IB modules, which has been used to increase the amount of functional materials in the BZ. Preliminary neutronic assessment performed in MCNP with the latest DEMO tokamak baseline design (2015) and sensitivity studies of the TBR [15] reveals a $\triangle \mathrm{TBR}$ between 0.1 and 0.2 with respect past designs, making a TBR of more than 1.20 feasible with the new "sandwitch" concept. The number of modules has been reduced to only 7 per segment and a completely new concept of manifold at the back supporting structure has been introduced. Figure 3 shows the evolution of the design from 2013 ("beer box") to the "sandwich" concept elaborated in 2015.

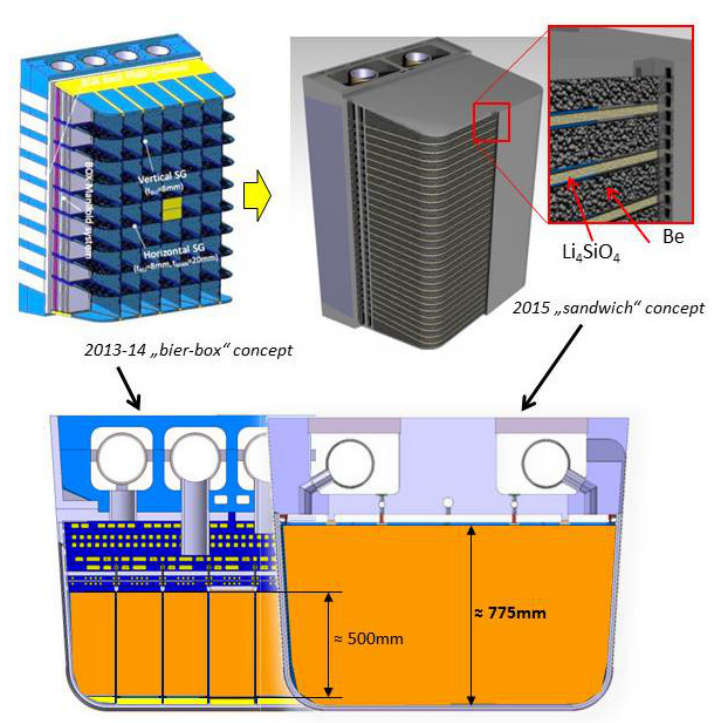

Fig. 3: Evolution of the HCPB design (2013-2015).

\subsection{The HCLL Concept}

This concept was proposed in 2003 and was included later at the end of the PPCS as model AB [16]. It uses helium as coolant and the eutectic Pb15.8Li as breeder material; PbLi circulates slowly in the blanket only to carry $\mathrm{T}$ outside the reactor for extraction. Like the HCPB it has been studied intensively for the TBM application. The main rationale followed by the CEA design team is to capitalize the experience acquired on the HCLL Test Blanket Module designed for ITER. Design improvements are being implemented to adapt the design to DEMO specifications and performance objectives.

The proposed design (see Figure 4) presents the typical "beer-box" architecture used in the TBM with Breeder Units. In particular the BSS has being designed following the tie rod concept used also in the TBM manifold region. Thermal and mechanical analyses have been carried out in order to justify the design of the HCLL breeding blanket showing attractive results for tie rods modules' attachments system and relatively good behavior of the box in case of LOCA when comparing to RCC-MRx criteria. CFD thermal analyses on generic breeding unit have enabled the consolidation of the results obtained with previous FEM design analyses [17].

Nuclear analyses are carried out at CEA with the TRIPOLI-4® Monte Carlo code. One of the objectives is to demonstrate consistency between the MCNP and TRIPOLI results on the HCLL breeding blanket. A very good agreement was obtained for all of the relevant nuclear responses [18]. The TBR predicted for the current design amount to 1.07. In order to achieve the TBR target of 1.1, suitable measures have been investigated: the increase of the inboard breeder zone thickness using an improved manifold scheme $(\triangle \mathrm{TBR}$ +0.01 per manifold), a reduction of the number of cooling plates in Breeding Units $(\triangle \mathrm{TBR}+0.02$ per cooling plate $)$ and stiffening plates $(\Delta \mathrm{TBR}+0.04$ removing the vertical stiffening grid). Such measures were shown to be sufficient to ensure the required TBR: the maximum theoretical TBR value that could be 
achieved by implementing all the different options is 1.19. Thermo-mechanical and thermo-hydraulical analysis are underway to determine the best viable options.

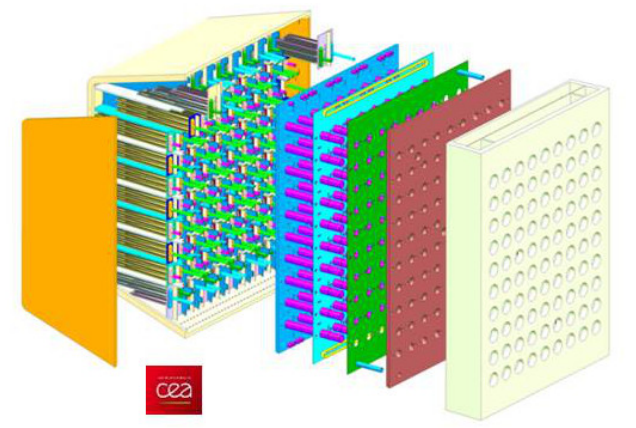

Fig. 4: HCLL design 2015.

\subsection{The WCLL Concept}

This concept was developed in parallel with the HCPB [19-20], but abandoned in 2004 for the HCLL. The studies have been restarted in 2012 first by CEA, then by the ENEA team. The concept is characterizes by the use of water at $\mathrm{PWR}$ conditions $\left(285-325^{\circ} \mathrm{C}\right.$ at $15.5 \mathrm{MPa}$ ) as coolant and $\mathrm{PbLi}$ as liquid breeder; the PbLi requirements are similar to those of the HCLL.

Figure 5 presents a new WCLL design (first release in 2015) based on the rationale of having the same repeatable basic geometry (modularity of the breeding blanket) along the poloidal direction. Stiffeners are placed in the radial-toroidal plane and in the radialpoloidal plane. The water cooling double wall tubes have a C-shape and they are placed horizontally (Fig. 2b). The calculated velocity in the tubes is less than $2 \mathrm{~m} / \mathrm{s}$. The PbLi flow path in the breeding zone is "quasi" horizontal. Thermal analyses are carried out [21] to evaluate the temperature field in the module. CFD code simulations are in progress to evaluate the PbLi flow in the module, to support the temperature field and the flow path in the collectors. Dedicated thermo-mechanical studies [22] have been performed on the water cooled FW to explore the cooling limits above the reference thermal load of $0.5 \mathrm{MW} / \mathrm{m}^{2}$ indicated as minimum in the design requirements.



Fig. 1: New WCLL design 2015.

\subsection{The DCLL Concept}

Also this concept can be found in the previous EU studies [23-24] and like the WCLL it was practically abandoned after the PPCS (a part some studies in the framework of the Spanish national programme TECNOFUS). The concept is interesting for the potentiality to operate at high $\mathrm{PbLi}$ temperatures (up to $700^{\circ} \mathrm{C}$ ) with high efficiency of the power conversion system. For the PPPT-DEMO a low temperature version (PbLi temperatures $<500^{\circ} \mathrm{C}$ ) as in DEMONET was proposed that does not require the development of high temperature materials making it possible for a near term application.

CIEMAT has been working on the new design since 2014, according to the new PPPT-DEMO reactor specifications [25]. The design is based on a multimodule segment, having 8 different modules attached to a common BSS. Each blanket module presents a poloidal circulation of PbLi in order to extract most of the reactor power, the FW including $\mathrm{He}$ channels for cooling purposes. The BZ consists of 4 parallel PbLi circuits, separated through stiffening grid radial walls. These channels include FCI consisting on Eurofer- aluminaEurofer sandwich, in order to prevent large MHD pressure drops. Thanks to the MMS design the PbLi velocity has been considerably reduced inside the modules $(2-3 \mathrm{~cm} / \mathrm{s})$ resulting in relatively low MHD pressure losses (about $250 \mathrm{kPa}$ in a preliminary estimation). A TBR of 1.13 has been estimated [26] and shielding performances have been assessed, demonstrating that the DCLL fulfills the current limit in the TF coils established for DEMO $\left(50 \mathrm{~W} / \mathrm{m}^{3}\right)$.


Fig. 6: DCLL design 2014-2015.

\section{Auxiliary systems, materials and R\&D}

As already mentioned before, the WPBB scope includes also the design of the TES and, for the liquid breeder blankets, the PbLi-loops. In addition several $\mathrm{R} \& \mathrm{D}$ packages have been launched to give the necessary support to the design activities.

\subsection{PbLi Technology}

Three of the four Breeder blankets concepts (HCLL/WCLL/DCLL) use the eutectic Pb-15.8Li alloy enriched to $90 \%$ in ${ }^{6} \mathrm{Li}$ as breeder; for these concepts $\mathrm{PbLi}$ loops have to provide circulation of the liquid 
metal through the BB internals. The design of these loops is a novelty of the present studies.

The design of these loops is based on the following functional requirements: a) to carry tritium produced inside the breeder modules to extraction units located outside the Vacuum Vessel, b) to control PbLi chemistry and remove accumulated impurities and (activated) corrosion products, c) to ensure gravitational draining of the BB module, $d$ ) to provide adequate heating in order to maintain $\mathrm{Pb}-16 \mathrm{Li}$ in the liquid state in all system locations, and d) for the DCLL to transport about $60 \%$ of the blanket heat (at temperature around $500^{\circ} \mathrm{C}$ ) to the steam generators.

The preliminary P\&ID of PbLi loops for the HCLL and WCLL was carried out in 2014-2015 together with the selection of the main components. During the normal operation, the PbLi alloy stored in a permanent tank (see Figure 6) is sent to IB and OB segments with permanent magnetic circulation pumps; the inlet flow can be heated if the temperature is lower than the required inlet one. Insulating valves are placed in the blanket inlet and outlet lines. The TES (see section 5.3) is placed on a bypass line; the alloy can be heated up to $450^{\circ} \mathrm{C}$ before entering in it. Behind the TES, the $\mathrm{Pb}-16 \mathrm{Li}$ flow is cooled down to $300^{\circ} \mathrm{C}$ (HCLL), or $326^{\circ} \mathrm{C}$ (WCLL) through heat exchangers. A portion of the flow enters in the Purification System (PS); the PS will be designed in order to manage a mass flow rate in the range between 1$10 \%$. An expansion tank is connected with the main loop in order to allow thermal expansion and recover of helium bubbles (produced in PbLi by neutron flux from the reactor).



Fig. 6: P\&ID of PbLi loops for the HCLL and WCLL.

The design of the PbLi-loop has to take into account several interconnected parameters, like corrosion of structural materials, development of permeation and corrosion coatings, design of purification system and chemistry control system, evaluation of helium generated per transmutation in the $\mathrm{BB}$, design of expansion tank, evaluation of pressure drop due to MHD effect and impact of MHD effect on corrosion rate, selection of pumping system, etc. In order to perform the design of the loops and $\mathrm{BB}$, dedicated multiphysics models are under development and the model will be validated with the support of the experimental facilities available in the frame of the BB project.

The computation of 3D MHD effects with thermal coupling, as well as tritium transport, have been performed for different benchmark problems that considered fully developed MHD flows in rectangular channels with various electrical boundary conditions. In MHD channel flows thin boundary layers form along all walls, whose thickness reduces by increasing the applied magnetic field [27-28]. The codes developed are under validation by means of MHD experiments at low and high velocity in the MEKKA laboratory at KIT.

Safety analysis of water/Pb-16Li interaction due to in WCLL in-box LOCA are ongoing in ENEA Brasimone [29].

\subsection{Solid breeders and beryllium}

Only one blanket concept, i.e. HCPB, is using lithium based ceramics for tritium breeding and beryllium / beryllides for neutron multiplying. The EUROfusion activities focus on the development and qualification of the currently pursued materials and the demonstration of upscaling their fabrication methods to mass production.

While presently either lithium orthosilicate (Li4SiO4) or lithium metatitanate ( $\mathrm{Li} 2 \mathrm{TiO} 3)$ are pursued by the ITER partners for the solid breeder concepts [30], advanced, mixed ceramics breeders were proposed within the European part of the BA DEMO R\&D activities. The chemical composition of the breeding ceramics was altered by adding lithium metatitanate as a second, strengthening phase to lithium orthosilicate [31] and a modified melt-based fabrication process was established at KIT [32]. As these mixed-phase ceramics are supposed to combine the advantages of lithium orthosilicate and lithium metatitanate, the further development and evaluation of these ceramics are carried out within the EUROfusion programme with the aim to qualify the material and to provide the necessary data for the conceptual design review of the HCPB concept. As the study of the thermal conductivity of ceramic pebble beds is a crucial issue for the design of the solid breeder blanket, a new facility based on the hot wire method was designed and assembled at KIT. First results showed that the thermal conductivity is hardly influenced by the additions of lithium titanate to orthosilicate. Investigations on the compatibility of breeding ceramics with structural materials like EUROFER under different purge gas atmospheres at TBM relevant temperatures are currently performed both, at CIEMAT and KIT. These complimentary studies use different experimental setups and are focused on the structural material and the ceramics, respectively. The long-term stability as well as the tritium sorption and release behavior of the advanced breeding ceramics will be investigated in the near future. A crucial point for the qualification of the advanced breeding ceramics is the investigation of their irradiation and tritium release behavior under neutron irradiation. Because of the present lack of neutron irradiation experiments, the 
hydrogen isotope diffusion and release characteristics under ionizing and nuclear radiations are all the more important to deduce the possible behavior of ceramics under neutron irradiation. First thermally induced outdiffusion studies of deuterium as well as studies under gamma-irradiation were already performed at CIEMAT [33-34-35].

The work package on neutron multiplier materials aims at a thorough and comprehensive investigation of presently available neutron multiplier materials. BeTi rods were successfully produced by KIT in cooperation with KBHF and the Technical University Berlin using a hot extrusion method. These rods will be used for production of titanium beryllide material by means of annealing of the rods. The BeTi rods will also be used to produce pebbles from titanium beryllide by rotation electrode method at JAEA, Rokkasho. In addition, Be pebbles produced at Brush Materion with the new production route based on the fluoride reduction method will be included in an extensive characterization programme, where these new materials will be compared to pebbles produced by the Bochvar Institute, and the 1 mm reference pebbles by NGK.

Besides ongoing compatibility studies with EUROFER 97, especially the compatibility of beryllium and titanium beryllide with air and steam will be investigated to assess kinetic data necessary to deduce the consequences for the fusion reactor blanket design. Furthermore, out-of-pile tritium absorption/release measurements will be performed on different types of neutron multiplier materials to improve and verify the empirical models. Beryllium pebbles irradiated in the HIDOBE-01 and HIDOBE-02 experiments in the HFR at NRG in Petten will also be included in these studies for comparison and to allocate the influence of helium on tritium release [36].

\subsection{Tritium Technology}

The R\&D activities on Tritium Technology for the $\mathrm{BB}$ have been articulated into four strongly interconnected main areas of work: Tritium System Design, tritium Transport Modelling, Tritium Extraction Processes, and Tritium Control. The following is a short description of the work programme and achievements so far; more details can be found in Demange [37].

Different candidate technologies to be used for the Tritium Extraction and Recovery System (TERS) have been carefully assessed along a multi-criteria analysis considering safety, integration, operation and performances, synergy with the inner fuel cycle, technology readiness level, costs, etc.... As outcome of this selection exercise, cryogenic trapping and Permeator Against Vacuum (PAV) have been pre-selected as baseline methods for the solid and liquid BBs, respectively. The following back-up solutions have also been retained for further considerations: membranes \& membranes reactors for TERS of HCPB, and Vacuum Sieved Tray (VST) for the PbLi liquid blankets. This technology pre-selection has been largely driven by the technology readiness level of the different processes that shall evolve along the experimental $R \& D$ phase. The preliminary pipe and flow diagrams for the TERS of the 4 BBs were produced.

The modelling of the Tritium Transport in the BB at system level has been reinitiated developing at first new models under Ecosimpro for HCPB and WCLL. The necessary inputs were compiled from latest BB designs and first estimates of tritium flows and inventories were computed. Parametric analysis at the macroscopic level were performed to analyze and identify possible operational points taking into account the performances of the TERS and additional measures like antipermeation barriers. Additional specific analyses at the microscopic level (including MHD effect, other boundary layers like oxide layers or coatings) will be progressively integrated to refine these first estimations.

Most of the methods to be used for the DEMO TERS are presently at a very low technology readiness level. Large efforts have been engaged to demonstrate that advanced and simple techniques would fulfill the high requirements in term of throughput and efficiency. Several facilities shall be deployed in different laboratories to implement experimental campaigns of twofold: i) proof of principle of the process based on laboratory scale experiments with tritium, and ii) proof of principle at component level throughout experiments with hydrogen or deuterium at medium scale. For HCPB, preliminary tests were done on Inorganic Membranes (IM) and Catalytic Membranes Reactors (CMR) mainly for screening the performances of different zeolite membranes (for IM) and different operation modes of a $\mathrm{Pd} / \mathrm{Ag}$ CMR [38]. For liquid blankets, two conceptual designs of lithium-lead loops for testing PAV at high velocity flows [39] and VST using tritium have been completed.

Efficient tritium control mitigation to limit the permeation towards the coolant is a key aspect and still challenging task. Experimental work will be dedicated to the measurements of permeation reduction factor of anticorrosion barriers with $\mathrm{D}_{2}$ under electron irradiation or with $\mathrm{T}_{2}$ after having been aged in PbLi or with neutron irradiation. Beyond coatings, the in-situ and on-line study of permeation through oxide layers promoted by He chemistry control $\left(\mathrm{H}_{2} / \mathrm{H}_{2} \mathrm{O}\right.$ addition) will also be investigated.

\subsection{Blanket FW and limiters}

The Breeding Blanket FW in the European DEMO will be a high heat flux, actively cooled component with tungsten armour for surface protection and plasma conditioning. The areas of activities in design and $R \& D$ in this sub-project are described in more detail in [40].

First, a key objective is to improve the definition of FW surface loading, i.e., that due to plasma radiation and fluxes of charged particles and neutrals. On the next level of activity, thermohydraulic and structural design calculations are performed to develop the FW operating requirements, coolant conditions and structural material constraints. With understanding of the requirements, the third level of design activity is on the FW plasma-facing 
components (PFCs). Here the work uses thermostructural analysis and assessment against recognised design criteria (RCC-MRX and ITER SDCIC) in the search for designs with improved power handling. The potential of plasma limiter components is also being explored as a way of accommodating high wall load events while maintaining acceptable wall neutron flux. However, this design activity requires clear understanding of cooling channel technology.

For the helium cooled FW concepts, heat transfer enhancement techniques are investigated which can increase, keeping the same design, the acceptable heat flux density from the currently established $0.5 \mathrm{MW} / \mathrm{m} 2$ to about $1 \mathrm{MW} / \mathrm{m}^{2}$ (for EUROFER structures). Ribbed surfaces and other turbulence or secondary flow inducing channel inserts can increase the heat transfer coefficient by factor 3-4. Alternatives are tested by experiments and by high fidelity fluid dynamics simulations, like the detached eddy (DES) technique [41]. Available fabrication techniques, in line with the general fabrication steps of the FW are a key issue for this work.

In the area of water cooled technology, work is ongoing to explore the technological limits of channel designs and how these could be employed in the DEMO PFCs. In the present work the performance of the wellknown Hypervapotron (HV) heat sink for a FW limiter application under DEMO operating conditions is predicted using CFD. In order to assess the performance, numerical simulations are performed using a commercial computational fluid dynamics code which was previously validated in predicting the thermal hydraulic performance of $\mathrm{HV}$ geometry [42]. Based on the results the potential usage of $\mathrm{HV}$ heat sink for DEMO reactor will be assessed.

\subsection{Blanket Manufacturing}

Activities are planned to assess the manufacturing feasibility of the different blanket designs. In addition critical manufacturing processes are investigated, producing and qualifying fabrication mock-ups. Tests of functional mock-up are planned in KIT and CVR facilities with helium and water at relevant conditions and chemistry. Within WPBB manufacturing technologies are being developed and qualified to comply with quality standards required by nuclear regulations.

In 2014 an assessment of technologies available for Breeding Blanket manufacturing was performed. These technologies have been developed in framework of the TBM programme under F4E, under EUROfusion or in national funded programme of association like CEA and KIT. In the TBM Programme [43] large contracts have been launched in the past few years for the assessment of fabrication technologies and procedures of the HCLL/HCPB TBM sub-components, like first wall, cooling and stiffening plates, and side caps; the investigated technologies are based on fusion and diffusion welding of EUROFER-97 steel as well as spark-erosion and bending. This work has developed preliminary fabrication/welding procedure specifications complying with codes and standards (RCC-MRx) and the manufacturing and characterisation of feasibility mock-ups. Also, assembly procedures for the TBM box have been developed for the establishment of an optimized assembly sequence/scenario and development of standardized welding procedure specifications. Additional work [44] has been performed for exploring alternative technologies aimed for the DEMO blanket development. These include spark erosion manufacturing of long FW channels ( $2 \mathrm{~m})$, bending of large FW plates and a variety of different welding procedures (laser, TIG and EB for plate thickness varying from 1 to $30 \mathrm{~mm}$ ) relevant for the assembly of the blanket box. Figure 5 shows an example of a structured FW channel (for heat transfer enhancement) realised with spark erosion technologies.

Dedicated tasks have been launched for special technology requested by single blanket design. E.g. double wall tube (DWT) for the WCLL concept that carries the water coolant inside the pool of PbLi that fills the blanket box. To increase the reliability of the concept, a compliant layer of copper joints two concentric EUROFER tubes, allowing crack stopping. The manufacturing of this component is still under development. Test experiments with specimens of DWT and EUROFER plates are planned for corrosion, corrosion fatigue, stress corrosion cracking and loss of fracture resistance. A dedicated test facility, the reactor water loop (RVS-3) installed in the experimental reactor LVR-15 in CVR, is currently instrumented for the test.

For the protection of the FW from plasma erosion the development of functionally graded tungstenEUROFER coating layers [45] has been started.

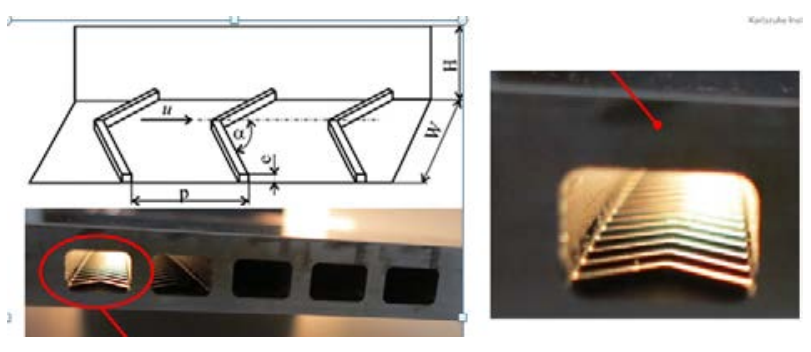

Fig. 2: Manufacturing of FW channels with helium heat transfer enhancing ribs (KIT courtesy).

\section{Summary and outlook}

After one year and half of work since its constitution in 2014, the breeding blanket project is now in fully operation. The requirements of the BB in the PPPT DEMO are under definition; in particular the heat load requirements of the $\mathrm{FW}$ are under investigation and uncertainties have to be reduced. The first version of the Design Description Document has been issued for all the four blankets investigated; the design work is concentrated to solve the main design requirements related to TBR, hydraulic lay-out and structural assessment. PbLi and tritium loops have been defined and the first P\&IDs are available. 
Almost all the necessary $R \& D$ for the conceptual design has been identified and implemented (e.g. tritium extraction and modelling, chemical compatibility of the breeders in operational and accidental conditions, manufacturing assessment).

\section{Acknowledgments}

This project has received funding from the European Union's Horizon 2020 research and innovation programme under grant agreement number 633053. The views and opinions expressed herein do not necessarily reflect those of the European Commission.

The author would like to thank R. Knitter, A. Li Puma, P. Vladimirov, V. Chakin, H. Neuberger and in general the whole BB Team for the contribution to this paper.

\section{References}

[1] F. Romanelli, et al., "Fusion Electricity - A Roadmap to the Realisation of Fusion Energy”, EFDA report (2012), ISBN 978-3-00-040720-8T

[2] G. Federici et al., "Overview of the design approach and prioritization of R\&D activities towards an EU DEMO”, this conference

[3] L.M. Giancarli et al., "Overview of the ITER TBM Program”, Fus. Eng. and Des. 87 (2012) 395-402.

[4] L.V. Boccaccini et al., "Present status of the conceptual design of the EU test blanket systems”, Fus. Eng. and Des. 86 (2011) 478-483.

[5] D. Maisonnier et al., "The European power plant conceptual study”, Fus. Eng. and Des. 75-79 (2005) 1173-1179

[6] L.A. El-Guebaly et al., "Technology-Related Challenges Facing Fusion Power Plants", in "Fusion Energy and Power: Applications, Technologies and Challenges" (2015), ISBN/ASIN: 978-1-63482-579-5.

[7] C. Bachmann et al., "Issues and strategies for DEMO invessel component integration”, this conference.

[8] A. Loving et al, "Pre-conceptual design assessment of DEMO remote maintenance”, Fus. Eng. and Des. 89 (2014) 9-10

[9] U. Fischer et al., "Neutronic performance issues of Breeder Blanket Options”, this conference

[10] G. Aiello et al., Assessment of design limits and criteria requirements for EUROFER structures in TBM components, Journal of Nuclear Materials, 414 (2011) 53-68.

[11] I.A. Maione et al., "Evaluation of EM loads distribution on DEMO blanket segments and their effect on mechanical integrity”, this conference.

[12] M. Dalle Donne (Ed.), European DEMO BOT solid breeder blanket, KfK 5429, Forschungszentrum Karlsruhe, 1994.

[13] S. Hermsmeyer et al., "Lay-out of the He-cooled solid breeder model B in the European power plant conceptual study”, Fus. Eng. and Des. 69 (2003) 281-287.

[14] P. Pereslavtsev et al., "Neutronic analyses of the HCPB DEMO reactor using a consistent integral approach",
Fus. Eng. and Des. 89 (2014) 1979-1983.

[15] P. Pereslavtsev et al., "Neutronic analyses of generic issues affecting the tritium breeding performance in different DEMO blanket concepts”, this conference.

[16] P. Sardain et al., "The European power plant conceptual study: Helium-cooled lithium-lead reactor concept”, Fus. Eng. and Des. 81 (2006) 2673-2678.

[17] J. Aubert et al., "Status on DEMO Helium Cooled Lithium Lead Breeding Blanket thermo-mechanical analyses”, this conference.

[18] J.-C. Jaboulay et al., "Nuclear Analysis of the HCLL blanket concept for the European DEMO using the TRIPOLI-4® Monte Carlo code”, this conference.

[19] L. Giancarli et al., "Overview of EU activities on DEMO liquid metal breeder blankets”, Fus. Eng. and Des. 27 (1995) 337-352.

[20] P. Sardain et al., "Power plant conceptual study: WCLL concept”, Fus. Eng. and Des. 69 (2003) 769-774.

[21] P. A. Di Maio et al., "Optimization of the breeder zone cooling tubes of the DEMO Water-Cooled Lithium Lead breeding blanket”, this conference.

[22] P. A. Di Maio et al., "On the optimization of the First Wall of the DEMO Water-Cooled Lithium Lead outboard breeding blanket equatorial module”, this conference.

[23] S. Malang and K. Schleisiek (Ed.), Dual coolant blanket concept, KfK-Report 5424 (1994).

[24] P. Norajitra et al., "Conceptual design of the dual-coolant blanket in the frame of the EU power plant conceptual study”, Fus. Eng. and Des. 69 (2003) 669-673.

[25] D. Rapisarda, "Overview of DCLL Research Activities in the EU/Spain”, 26th IEEE Symposium on Fusion Engineering (SOFE), Austin, Texas, USA (2015).

[26] I. Palermo, "Neutronic analyses of the preliminary design of a DCLL blanket for the EUROfusion DEMO power plant”, this conference.

[27] L. Bühler and C. Mistrangelo, "Theoretical Studies of MHD Flows in Support to HCLL Design Activities”, this conference.

[28] C. Mistrangelo and L. Bühler, "Electro-magnetic Flow Coupling for Liquid Metal Blanket Applications", this conference.

[29] M. Eboli et al., "Implementation of the Chemical $\mathrm{PbLi} /$ Water Reaction in the SIMMER Code", this conference.

[30] R. Knitter et al., "Recent developments of solid breeder fabrication”, J. Nucl. Mater. 442 (2013) 420-424.

[31] R. Knitter et al., "Fabrication of modified lithium orthosilicate pebbles by addition of titania”, J. Nucl. Mater. 442 (2013) 433-436.

[32] M. Kolb et al., "Enhanced fabrication process for lithium orthosilicate pebbles as breeding material”, Fus. Eng. Design 86 (2011) 2148-2151.

[33] M. González et al., “Thermally induced outdiffusion studies of deuterium in ceramic breeder blanket materials after irradiation”, Fusion Eng. Design (2015), http://dx.doi.org/10.1016/j.fusengdes.2015.03.027.

[34] M. González et al., "The Deuterium release behaviour in candidate gamma ray irradiated candidate breeder ceramics”, CBBI-18, 10-12. September 2015, Jeju, 
Korea.

[35] E. Carella et al., "Deuterium trapping and release processes occurring in $\gamma$-irradiated solid breeder blanket materials”, ICFRM-17, 12-16 October 2015, Aachen, Germany.

[36] V. Chakin et al., “Tritium Release from Titanium Beryllide after High-Temperature Loading by Tritium/Protium Gas Mixture“, this conference.

[37] D. Demange et al.: "Tritium Extraction Technologies and DEMO Requirements”, this conference.

[38] A. Santucci et al., "Catalytic membrane reactor for tritium extraction system from He purge”, this conference.

[39] I. Fernández, "Conceptual design of a lithium-lead loop for testing the permeator against vacuum technique at high velocity flows", this conference.

[40] T.R. Barrett et al., "Progress in the Engineering Design and Assessment of the European DEMO First Wall and Divertor Plasma Facing Components”, this conference.

[41] S. Ruck and F. Arbeiter, "Thermohydraulics of RibRoughened Helium Gas Running Cooling Channels for First Wall Applications”, this conference.

[42] P.K. Domalapally et al., "Assessment of Hypervapotron Heat Sink Performance using CFD under DEMO Relevant First Wall Conditions”, this conference.

[43] M. Zmitko et al., "The European ITER Test Blanket Modules: Current status of fabrication technologies development and a way forward”, Fus. Eng. and Des., In Press.

[44] H. Neuberger et al., "Overview on ITER and DEMO blanket fabrication activities of the KIT INR and related frameworks", Fus. Eng. and Des., In Press.

[45] D.D. Qu and al., "Functionally graded tungsten/EUROFER coating for first wall application”, this conference. 